\title{
Modifiable cardiovascular risk factors in adults aged 40-79 years in Germany with and without prior coronary heart disease or stroke
}

\author{
Julia Truthmann ${ }^{1 *}$, Markus A. Busch¹, Christa Scheidt-Nave ${ }^{1,2}$, Gert B. M. Mensink ${ }^{1,2}$, Antje Gößwald1, \\ Matthias Endres $2,3,4,5$ and Hannelore Neuhauser ${ }^{1,2}$
}

\begin{abstract}
Background: Control of modifiable cardiovascular disease (CVD) risk factors has substantially reduced CVD mortality, but risk factor levels in populations may change and need continuous monitoring. This study aims to provide current estimates of the prevalence of these risk factors in Germany according to sex and history of coronary heart disease (CHD) or stroke.

Methods: The analyses were based on data from the German Health Interview and Examination Survey for Adults (DEGS1; age 40-79 years, $n=5101$ ), which is a cross-sectional population-based examination survey. CVD risk factors were defined according to recommendations in the European Guidelines on Cardiovascular Disease Prevention in Clinical Practice 2012.

Results: The mean age was 57 years and $52 \%$ were female; 493 participants had prior CHD and 163 participants a prior stroke. The overall prevalence of behavioural risk factors ranged from $17.9 \%$ for high risk alcohol consumption to $90 \%$ for low vegetable intake. Blood pressure $\geq 140 / 90 \mathrm{mmHg}$ was found in $21 \%$ and $69 \%$ had total cholesterol $\geq 5.0 \mathrm{mmol} / \mathrm{l}$. Only $16 \%$ met the targets for five behavioural factors combined (smoking, physical activity, fruit intake, alcohol intake and obesity), $13 \%$ of those with and $16 \%$ of those without CHD or stroke. The prevalences of most behavioural risk factors were higher among men compared to women.

Conclusions: There is a high prevention potential from modifiable cardiovascular risk factors in the general population aged 40-79 years in Germany and among those with prior CHD or stroke. Risk factors are often co-occurring, are interrelated and require combined educational, behavioral, medical and policy approaches.
\end{abstract}

Keywords: Coronary heart disease, Stroke, Prevention, Risk factors

\section{Background}

Cardiovascular disease (CVD) is the most common cause of death before the age of 65 in Europe [1]. However, a substantial proportion of these deaths may be preventable through changes in lifestyle [2]. The European Guidelines on cardiovascular disease prevention in clinical practice 2012 (ESC 2012) [3] made the following key recommendations to lower CVD risk: quit smoking, increase physical activity, eat a healthy diet, limit alcohol consumption, reduce body weight, reduce blood pressure (BP) and control blood

\footnotetext{
* Correspondence: TruthmannJ@rki.de

${ }^{1}$ Department of Epidemiology and Health Monitoring, Robert Koch Institute, Berlin, Germany

Full list of author information is available at the end of the article
}

lipids. Men and women with established CVD are at very high risk for future events and prompt interventions on risk factors are recommended. However, CVD risk factors often remain uncontrolled $[4,5]$, and up-to-date data on the prevention potential of modifiable risk factors in the general population as well as in high-risk groups are difficult to obtain.

The aim of this cross-sectional study is to contribute to the debate on CVD prevention by providing up-to-date estimates of CVD risk factor proportions of the principal modifiable CVD risk factors in adults aged 40-79 years in Germany with data from the nationwide population-based

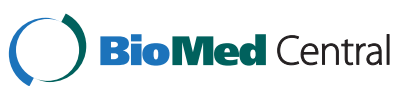


German Health Interview and Examination Survey for Adults (DEGS1) [6]. In addition, the study presents risk factor prevalences among persons with and without prior coronary heart disease (CHD) or stroke.

\section{Methods}

\section{Study design and sample}

The first wave of the German Health Interview and Examination Survey for Adults (DEGS1) was conducted in 2008-2011 with the aim to obtain comprehensive information about the health of the residential population aged 18-79 years living in Germany. Design and methods were described in detail elsewhere [6-8]. The survey comprises 8151 men and women who live in Germany, including 4192 first-time participants and 3959 persons who already participated in the German National Health Interview and Examination Survey 1998 (GNHIES98) [8]. Exclusion criteria for the present analysis are presented in Fig. 1 resulting in a final study sample of 5101 participants (2436 men, 2665 women).

The DEGS1 study was approved by the Federal and State Commissioners for Data Protection and the Charité Universitätsmedizin Berlin ethics committee (No. EA2/ 047/08). All participants provided written informed consent prior to the interview and examination.

\section{Data collection and study variables}

The modifiable risk factors were defined according to recommendations of the ESC 2012 guideline [3]. As part of a general self-administered health questionnaire, daily

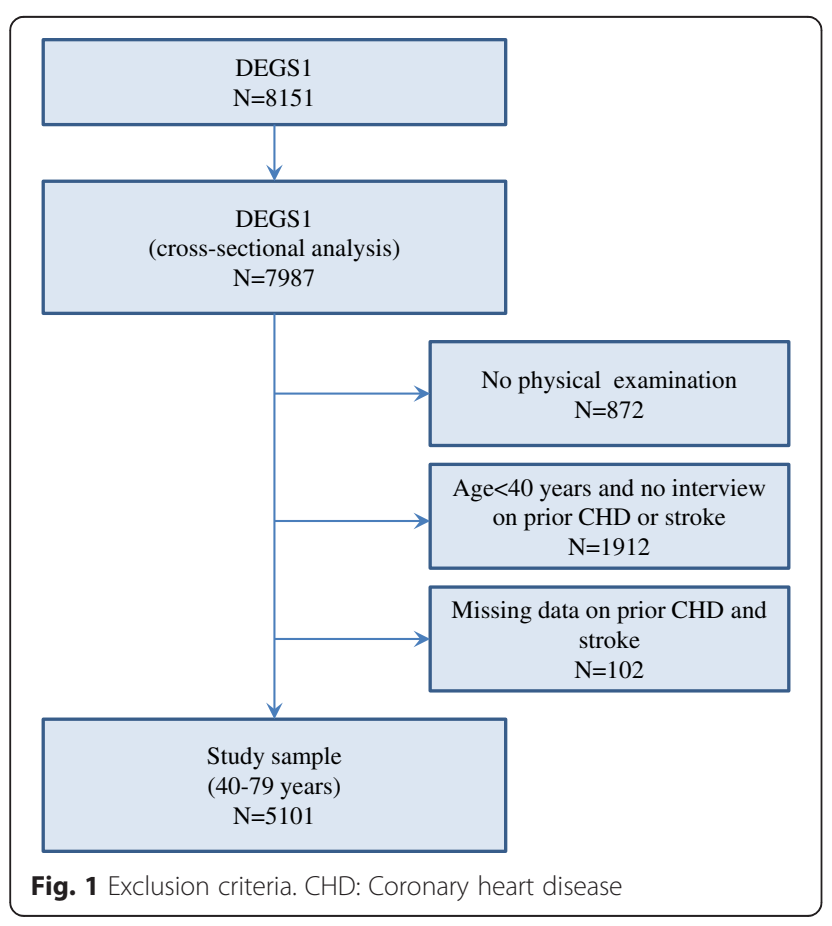

smoking was assessed with several questions. Physical activity within a usual week was also assessed within this questionnaire and defined as low when $<2.5 \mathrm{~h}$ physical activity/ week [9] and physical inactive when no physical activity was reported. A semi-quantitative self-administered food frequency questionnaire was used to assess the frequency and portion size of 53 food items for a reference period of the past four weeks. The number of servings of fruit (fresh and cooked) and vegetable (fresh and cooked vegetable, legumes) and servings of fish (cold fish and fish as a hot meal) per day were calculated by combining the frequency of consumption and the usual portion size. Low fruit intake was defined as $<2$ portions fruit per day, low vegetable intake as $<2$ portions vegetable per day and low fish intake as $<1$ portion fish per week. Quantity of alcohol intake was calculated by summing the alcohol content of consumed beer, non-alcoholic beer (still containing minute alcohol amounts), wine, spirits [10] and cocktails (assuming one cocktail to contain $15.0 \mathrm{~g}$ of alcohol [11]). High alcohol consumption was defined as $>10 \mathrm{~g}$ alcohol per day in women and $>20 \mathrm{~g}$ alcohol per day in men. Since zero alcohol consumption has been related to increased cardiovascular risk and mortality, a separate category was defined as alcohol intake of $0 \mathrm{~g} /$ day [3]. Body weight was measured with an electronic scale and body height was measured using a portable stadiometer. The body mass index (BMI) was calculated as BMI $\left[\mathrm{kg} / \mathrm{m}^{2}\right]=$ body weight $[\mathrm{kg}] /$ body height $^{2}[\mathrm{~m}]$. A BMI $\geq 25 \mathrm{~kg} / \mathrm{m}^{2}$ was defined as overweight and a BMI $\geq 30 \mathrm{~kg} / \mathrm{m}^{2}$ was defined as obesity [12]. Three sitting blood pressure (BP) measurements were taken after a five-minute rest on the right arm following a standardized protocol with an automated oscillometric device (Datascope Accutorr Plus) and the prevalence of BP above $\geq$ $140 \mathrm{mmHg}$ systolic or above $\geq 90 \mathrm{mmHg}$ diastolic was determined using the mean of the second and third BP measurements. Total cholesterol (TC) and high density lipoprotein cholesterol (HDL) were measured using an enzymatic assay (Architect ci8200, Abbott, Germany). Elevated TC was defined as a value $\geq 5.0 \mathrm{mmol} / \mathrm{l}(190 \mathrm{mg} / \mathrm{dl})$ and an additional cut-off of $6.2 \mathrm{mmol} / \mathrm{l}(240 \mathrm{mg} / \mathrm{dl})$ was included based on previous guidelines [13]. Non-HDL was calculated by subtracting HDL from TC. Elevated nonHDL was defined as $\geq 3.8 \mathrm{mmol} / \mathrm{l}$ among participants without prior CHD or stroke and $\geq 2.6 \mathrm{mmol} / \mathrm{l}$ among those with prior CHD or stroke. Previous diagnoses of $\mathrm{CHD}$, stroke, hypertension and dyslipidaemia were assessed in a standardized physician interview. Medications taken in the previous seven days were coded according to the Anatomical Therapeutic Chemical (ATC) classification system. Medications from ATC-group C10 were counted as lipid-lowering when dyslipidaemia was known. Similarly, medications from ATC groups C03, C07, C08, C09 and $\mathrm{C} 02$ were defined as antihypertensive in those with known hypertension. 


\section{Analysis}

For the descriptive analyses percentages and $95 \%$ confidence intervals were calculated. In order to account for the unequal sampling probabilities related to the sampling design and nonresponse, statistical analyses were weighted using a weighting factor [8] and the complex survey sampling was taken into account using complex samples procedures in SPSS version 20.0 (SPSS Inc., Chicago, Illinois, USA). P values less than 0.05 were considered statistically significant. The analyses were stratified for prior CHD or stroke, sex and age. Furthermore, the prevalences of cardiovascular risk factors were calculated according to obesity status, BP level and TC level group. For analysis of behavioural risk factor combinations, we considered five categories represented by one indicator each: daily smoking, physical activity $<2.5 \mathrm{~h} /$ week, $<2$ portions of fruit/day, alcohol intake $>10 \mathrm{~g} /$ day in women or $>20 \mathrm{~g} /$ day in men, and $\mathrm{BMI} \geq 30 \mathrm{~kg} / \mathrm{m}^{2}$.

\section{Results}

The mean age of the study population was 57 years and $52 \%$ were female. The prevalence of $\mathrm{CHD}$ was $9 \%$ (95\% CI 8-10) and the prevalence of stroke was $3 \%$ (95\% CI 2-3). The prevalence of prior CHD or stroke was $11 \%$ (95\% CI 10-12). The mean age of the group with $\mathrm{CHD}$ or stroke was 67 years and $35 \%$ were female. Table 1 shows the distribution of cardiovascular risk factors for the overall sample and for participants with and without prior CHD or stroke separately. The overall prevalence of behavioral risk factors ranged from $18 \%$ for high risk alcohol consumption and $20 \%$ for daily smoking to $82 \%$ for low physical activity and $90 \%$ for low vegetable intake. $\mathrm{BP} \geq 140 / 90 \mathrm{mmHg}$ was found in $21 \%$ and $69 \%$ had $\mathrm{TC} \geq 5.0 \mathrm{mmol} / \mathrm{l}$ (including $27 \%$ with $\mathrm{TC} \geq 6.2 \mathrm{mmol} / \mathrm{l}$ ).

The prevalence of behavioural risk factors (daily smoking, insufficient physical activity, insufficient fruit, vegetable and fish intake, high alcohol intake) was similar in participants with and without prior CHD or stroke. Participants with CHD or stroke were significantly more likely to be physically inactive, overweight and/or obese. Prevalence of BP $\geq 140 / 90 \mathrm{mmHg}$ was similar in both groups. Participants with prior CHD or stroke were less likely to have elevated TC, but had a higher prevalence of elevated non-HDL ( $\geq 2.6 \mathrm{mmol} / \mathrm{l}$; see Additional file 1, Table S1) compared to participants without prior CHD or stroke ( $\geq 3.8 \mathrm{mmol} / \mathrm{l})$. Also, participants with prior $\mathrm{CHD}$ or stroke with $\mathrm{BP} \geq 140 / 90 \mathrm{mmHg}$ or elevated TC were less likely to be unaware of their hypertension or hyperlipidaemia, respectively and those aware were more likely to be treated.

Table 1 Prevalence of cardiovascular risk factors (95\% confidence interval) among adults aged 40-79 years

\begin{tabular}{|c|c|c|c|c|}
\hline Risk factor & $\begin{array}{l}\text { Total } \\
(N=5101)\end{array}$ & $\begin{array}{l}\text { No CHD or stroke } \\
(N=4489)\end{array}$ & $\begin{array}{l}\text { CHD or stroke } \\
(N=612)\end{array}$ & $P$ \\
\hline Daily smoking & $19.8(18-21.7)$ & $20.2(18.3-22.2)$ & $16.5(12.4-21.6)$ & 0.200 \\
\hline$<2.5$ h physical activity/week & $82.4(80.9-83.7)$ & $82.2(80.7-83.6)$ & $84.1(79.9-87.6)$ & 0.400 \\
\hline Physically inactive (no physical activity in average week) & $34.2(32.3-36.4)$ & $32.4(30.3-34.6)$ & $49.8(44.4-55.3)$ & $<0.001$ \\
\hline$<2$ portions fruit/day & $66.1(64.3-67.8)$ & $65.8(63.9-67.7)$ & $68.1(63-72.8)$ & 0.400 \\
\hline$<2$ portions vegetable/day & $90.4(89.2-91.5)$ & $90.1(88.8-91.3)$ & $92.8(89.3-95.2)$ & 0.100 \\
\hline$<1$ portion fish/week & $67.3(65.5-69.1)$ & $66.8(64.9-68.7)$ & $71.6(66.5-76.2)$ & 0.100 \\
\hline Alcohol intake > $10 \mathrm{~g} /$ day (women) or $20 \mathrm{~g} /$ day (men) & $17.9(16.5-19.4)$ & $18(16.7-19.5)$ & $16.7(12.9-21.4)$ & 0.600 \\
\hline Alcohol intake $=0 \mathrm{~g} /$ day & $12.7(11.3-14.3)$ & $12.4(10.8-14.2)$ & $15.2(11.7-19.5)$ & 0.200 \\
\hline Overweight (BMl $\geq 25 \mathrm{~kg} / \mathrm{m}^{2}$ ) & $69.9(68.2-71.5)$ & $68(66.3-69.8)$ & $85.1(81.2-88.3)$ & $<0.001$ \\
\hline Obesity (BMl $\left.\geq 30 \mathrm{~kg} / \mathrm{m}^{2}\right)$ & $28.4(26.6-30.2)$ & $26.5(24.8-28.3)$ & $43.1(37.4-48.9)$ & $<0.001$ \\
\hline $\mathrm{BP} \geq 140 / 90 \mathrm{mmHg}$ & $20.6(18.9-22.4)$ & $20.7(18.9-22.5)$ & $20(16.1-24.5)$ & 0.700 \\
\hline Proportion unaware among those with $\mathrm{BP} \geq 140 / 90 \mathrm{mmHg}$ & $33.5(30.2-37)$ & $36(32.5-39.7)$ & $12.1(6.6-21.3)$ & $<0.001$ \\
\hline Proportion treated and aware ${ }^{b}$ among those with $B P \geq 140 / 90 \mathrm{mmHg}$ & $45.4(41.9-49)$ & $42.5(38.8-46.3)$ & $70.6(59.2-79.9)$ & $<0.001$ \\
\hline Elevated TC $(\geq 5.0 \mathrm{mmol} / \mathrm{l})$ & $68.8(66.5-71)$ & $71.2(68.9-73.5)$ & $48.9(43.6-54.1)$ & $<0.001$ \\
\hline Highly elevated TC ( $\geq 6.2 \mathrm{mmol} / \mathrm{l})$ & $24.7(22.9-26.6)$ & $25.9(23.9-27.9)$ & $15.2(11.6-19.7)$ & $<0.001$ \\
\hline Proportion unaware among those with $\mathrm{TC} \geq 5.0 \mathrm{mmol} / \mathrm{l}$ & $57.5(55.3-59.7)$ & $59.4(57-61.7)$ & $35.0(28.6-42)$ & $<0.001$ \\
\hline Proportion treated and aware ${ }^{\mathrm{b}}$ among those with $\mathrm{TC} \geq 5.0 \mathrm{mmol} / \mathrm{l}$ & $9.1(8-10.3)$ & $7.5(6.4-8.7)$ & $28.3(22.4-35.1)$ & $<0.001$ \\
\hline
\end{tabular}

$P$ values less than 0.05 were considered statistically significant (bold)

$B M I$ body mass index, BP blood pressure, CHD coronary heart disease, $T C$ total cholesterol

${ }^{a}$ defined as reported diagnosis of hypertension or dyslipidaemia

${ }^{b}$ defined as reported diagnosis of hypertension or dyslipidaemia in combination with reported use of antihypertensive or lipid-lowering drugs, respectively 
The proportions of risk factors stratified for men and women are shown in Table 2. Compared to women, the prevalence of smoking, low fruit, vegetable and fish intake, high alcohol intake, overweight,
$\mathrm{BP} \geq 140 / 90 \mathrm{mmHg}$ and non-HDL $\geq$ target was higher among men. In contrast, women were more often physically inactive and exceeded more often both cut offs for TC.

Table 2 Prevalence of cardiovascular risk factors (95\% confidence interval) among men and women aged 40-79 years

\begin{tabular}{|c|c|c|c|c|c|c|c|c|}
\hline \multirow[t]{2}{*}{ Risk factor } & \multicolumn{4}{|l|}{ Men } & \multicolumn{4}{|l|}{ Women } \\
\hline & $\begin{array}{l}\text { Total } \\
(N=2436)\end{array}$ & $\begin{array}{l}\text { No } C H D \\
\text { or stroke } \\
(N=2040)\end{array}$ & $\begin{array}{l}\text { CHD or Stroke } \\
(N=396)\end{array}$ & $P$ & $\begin{array}{l}\text { Total } \\
(N=2665)\end{array}$ & $\begin{array}{l}\text { No } C H D \\
\text { or stroke } \\
(N=2449)\end{array}$ & $\begin{array}{l}\text { CHD or Stroke } \\
(N=216)\end{array}$ & $P$ \\
\hline \multirow[t]{2}{*}{ Daily smoking } & 21.6 & 22.4 & 16.4 & 0.100 & 18 & 18.2 & 16.7 & 0.700 \\
\hline & $(19.1-24.3)$ & $(19.5-25.6)$ & $(11.5-22.9)$ & & $(16.1-20.2)$ & $(16.2-20.3)$ & $(10.2-26)$ & \\
\hline \multirow[t]{2}{*}{$<2.5$ h physical activity/week } & 80 & 79.6 & 82.7 & 0.300 & 84.7 & 84.5 & 86.4 & 0.600 \\
\hline & $(77.8-82.1)$ & $(77.2-81.8)$ & $(76.9-87.3)$ & & $(82.8-86.4)$ & $(82.5-86.3)$ & $(79-91.5)$ & \\
\hline \multirow{2}{*}{$\begin{array}{l}\text { Physically inactive (no physical } \\
\text { activity in average week) }\end{array}$} & 32.3 & 29.8 & 48.1 & $<0.001$ & 36.2 & 34.8 & 52.9 & $<0.001$ \\
\hline & $(29.7-35.1)$ & $(27-32.7)$ & $(40.8-55.5)$ & & $(33.6-39)$ & $(32.1-37.7)$ & $(44-61.7)$ & \\
\hline \multirow[t]{2}{*}{$<2$ portions fruit/day } & 71 & 71.5 & 67.7 & 0.300 & 61.3 & 60.7 & 68.8 & 0.100 \\
\hline & $(68.5-73.3)$ & $(68.9-74)$ & $(60.9-73.9)$ & & $(58.9-63.7)$ & $(58.2-63.1)$ & $(60.8-75.8)$ & \\
\hline \multirow[t]{2}{*}{$<2$ portions vegetable/day } & 93.9 & 93.8 & 93.7 & 0.900 & 87 & 86.7 & 90.7 & 0.200 \\
\hline & $(92.4-95.1)$ & $(92.7-95.1)$ & $(88.8-96.9)$ & & $(85-88.8)$ & $(84.5-88.6)$ & $(85.1-94.3)$ & \\
\hline \multirow[t]{2}{*}{$<1$ portions fish/week } & 66.5 & 64.8 & 70.2 & 0.100 & 69.1 & 68.6 & 74 & 0.200 \\
\hline & $(63.1-67.9)$ & $(62.2-67.3)$ & $(64.1-75.6)$ & & $(66.5-71.5)$ & $(66-71.2)$ & $(65.7-80.8)$ & \\
\hline \multirow{2}{*}{$\begin{array}{l}\text { Alcohol intake }>10 \mathrm{~g} / \text { day (women) } \\
\text { or } 20 \mathrm{~g} / \text { day (men) }\end{array}$} & 21.4 & 21.3 & 21.9 & 0.800 & 14.4 & 15 & 7.6 & 0.100 \\
\hline & $(19.2-23.6)$ & $(19.1-23.6)$ & $(16.5-28.5)$ & & $(12.7-16.3)$ & $(13.2-16.9)$ & $(3.5-15.6)$ & \\
\hline \multirow[t]{2}{*}{ Alcohol intake $=0 \mathrm{~g} / \mathrm{day}$} & 8 & 8 & 8.5 & 0.800 & 17.4 & 16.6 & 27.1 & 0.005 \\
\hline & $(6.6-9.6)$ & $(6.3-10)$ & $(5.1-13.7)$ & & $(15.3-19.8)$ & $(14.4-19.2)$ & $(20.2-35.3)$ & \\
\hline \multirow[t]{2}{*}{ Overweight (BMI $\geq 25 \mathrm{~kg} / \mathrm{m}^{2}$ ) } & 77.6 & 76.2 & 85.9 & 0.001 & 62.4 & 60.5 & 83.6 & $<0.001$ \\
\hline & $(75.4-79.6)$ & $(73.8-78.5)$ & $(81.1-89.7)$ & & $(60-64.8)$ & $(58-63)$ & $(77.2-88.5)$ & \\
\hline \multirow[t]{2}{*}{ Obesity (BMl $\geq 30 \mathrm{~kg} / \mathrm{m}^{2}$ ) } & 27.8 & 25.7 & 40.3 & $<0.001$ & 28.9 & 27.2 & 47.8 & $<0.001$ \\
\hline & $(25.2-30.6)$ & $(23.2-28.5)$ & $(33.2-47.8)$ & & $(26.5-31.4)$ & $(24.8-29.8)$ & $(38.8-57)$ & \\
\hline \multirow[t]{2}{*}{$\mathrm{BP} \geq 140 / 90 \mathrm{mmHg}$} & 23.4 & 23.8 & 20.9 & 0.300 & 17.8 & 17.8 & 18.4 & 0.800 \\
\hline & $(21.1-25.9)$ & $(21.4-26.4)$ & $(16.1-26.7)$ & & $(15.8-20.1)$ & $(15.7-20.1)$ & $(12.4-26.2)$ & \\
\hline \multirow{2}{*}{$\begin{array}{l}\text { Proportion of unaware among } \\
\text { those with } B P \geq 140 / 90 \mathrm{mmHg}\end{array}$} & 36.1 & 39.6 & 10.3 & $<0.001$ & 30.3 & 31.6 & 15.6 & 0.100 \\
\hline & $(31.3-41.1)$ & $(34.6-44.9)$ & $(4.2-23.1)$ & & $(25.5-35.5)$ & $(26.5-37.2)$ & $(6.7-32.3)$ & \\
\hline \multirow{2}{*}{$\begin{array}{l}\text { Proportion treated and aware } \\
\text { among those with } \mathrm{BP} \geq \\
140 / 90 \mathrm{mmHg}\end{array}$} & 40.5 & 36 & 73.2 & $<0.001$ & 51.7 & 50.4 & 65.6 & 0.100 \\
\hline & $(35.3-46.1)$ & $(30.6-41.8)$ & $(58-84.3)$ & & $(46.6-56.8)$ & $(45.3-55.6)$ & $(46.9-80.5)$ & \\
\hline \multirow{2}{*}{$\begin{array}{l}\text { Elevated total cholesterol }(\mathrm{TC} \geq \\
5.0 \mathrm{mmol} / \mathrm{l})\end{array}$} & 65.2 & 68.8 & 43.6 & $<0.001$ & 72.3 & 73.4 & 59.4 & $<0.001$ \\
\hline & $(62.1-68.2)$ & $(65.6-71.9)$ & $(33.6-49.5)$ & & $(69.7-74.8)$ & $(70.7-76)$ & $(50.9-67.3)$ & \\
\hline \multirow[t]{2}{*}{ Highly elevated TC ( $\geq 6.2 \mathrm{mmol} / \mathrm{l})$} & 22.8 & 24.5 & 12.6 & 0.001 & 26.5 & 27.1 & 19.7 & 0.100 \\
\hline & $(20.4-25.4)$ & $(21.9-27.3)$ & $(8.3-18.6)$ & & $(24.1-29.1)$ & $(24.6-29.8)$ & $(13.6-27.8)$ & \\
\hline \multirow{2}{*}{$\begin{array}{l}\text { Proportion of unaware among } \\
\text { those with } T C \geq 5.0 \mathrm{mmol} / \mathrm{l}\end{array}$} & 57.3 & 59.4 & 36.5 & $<0.001$ & 57.7 & 59.4 & 33.1 & $<0.001$ \\
\hline & $(53.9-60.6)$ & $(55.7-62.9)$ & $(27.2-47.1)$ & & $(54.7-60.7)$ & $(56.3-62.5)$ & $(23.6-44.2)$ & \\
\hline \multirow{2}{*}{$\begin{array}{l}\text { Proportion treated and aware }{ }^{b} \\
\text { among those with } T C \geq 5.0 \mathrm{mmol} / \mathrm{l}\end{array}$} & 8.9 & 6.8 & 29.7 & $<0.001$ & 9.3 & 8.1 & 26.6 & $<0.001$ \\
\hline & $(7.3-10.7)$ & $(5.4-8.4)$ & $(21.1-40.1)$ & & $(7.7-11.2)$ & $(6.5-10)$ & $(18.5-36.7)$ & \\
\hline
\end{tabular}

$P$ values less than 0.05 were considered statistically significant (bold)

$B M I$ body mass index, $B P$ blood pressure, $C H D$ coronary heart disease, $T C$ total cholesterol

a defined as reported diagnosis of hypertension or dyslipidaemia

${ }^{b}$ defined as reported diagnosis of hypertension or dyslipidaemia in combination with reported use of antihypertensive or lipid-lowering drugs, respectively 
Age-group specific analyses revealed higher or equal proportions of most unfavourable risk factor levels in the older age group (see Additional file 1). As exceptions, smoking prevalence and proportion of unaware persons with elevated TC $(\geq 5.0 \mathrm{mmol} / \mathrm{l})$ were lower in older men and women and high alcohol intake was less frequent in older women.

The risk factor prevalences stratified by obesity group, BP target and TC target groups are presented in Additional file 2. Compared to non-obese participants, prevalence of $\mathrm{BP} \geq 140 / 90 \mathrm{mmHg}$ and zero alcohol consumption was higher among obese participants. In contrast, non-obese participants were more often physically inactive and exceeded more often the recommended alcohol intake. Compared to participants with $\mathrm{BP}<140 / 90 \mathrm{mmHg}$ prevalence of alcohol intake, TC $\geq 5.0 \mathrm{mmol} / \mathrm{l}$, overweight and obesity was higher, and the prevalence of smoking was lower among the group with $\mathrm{BP} \geq 140 / 90 \mathrm{mmHg}$. Except for BP, no difference could be observed between the TC target groups.

Figure 2 shows the combination of five behavioural risk factors. Only $15 \%$ had none of these risk factors, $39 \%$ had one risk factor, and $45 \%$ had two or more risk factors. More women than men had no risk factor $(12 \%$ (95\% CI 11-14) vs. $19 \%$ (95\% CI 17-21)). More than half of the CHD or stroke group and about $44 \%$ of the group without prior $\mathrm{CHD}$ or stroke had two or more risk factors. Women with $\mathrm{CHD}$ or stroke more often had a combination of two or more behavioural risk factors compared to women without CHD or stroke (52\% (95\% CI 44-61) vs. $39 \%$ (95 \% CI 37-42)).

\section{Discussion}

The results of this cross-sectional analysis of modifiable cardiovascular risk factors in adults in Germany suggest that, for the vast majority of adults in Germany, there is a high prevention potential for all of the behavioural risk factors investigated in this study: daily smoking, insufficient fruit, vegetable and fish consumption, high alcohol intake, insufficient physical activity and overweight. Almost $85 \%$ of adults aged $40-79$ years have at least one of these risk factors, with $45 \%$ having a combination of two or more risk factors.

Studies on CVD risk factors in different countries are often difficult to compare due to differences in the specific combinations and definitions of the risk factors that were assessed. In the United States adherence to five healthy behavioural factors (including fruit and vegetable consumption, regular exercise, healthy weight, alcohol consumption and smoking) in 40 to 74 year olds was as low as $8 \%$ in 2006 and had decreased from $15 \%$ in 1988 [14]. A recent analysis from Italy on six cardiovascular risk factors (smoking, low fruit/vegetable consumption, obesity/overweight, hypertension, dyslipidaemia and diabetes) found that $90 \%$ of the study population had more than one and $84 \%$ had between two and five risk factors [15].

For BP and TC, we report prevalences of elevated, i.e., uncontrolled values as measured in our study. These prevalences do not include controlled hypertension or controlled hypercholesterolemia. It is encouraging that the target BP $(<140 \mathrm{mmHg}$ systolic and $<90 \mathrm{mmHg}$ diastolic $)$ was reached by almost $80 \%$ of the participants but this proportion may be lower among severely ill patient groups.

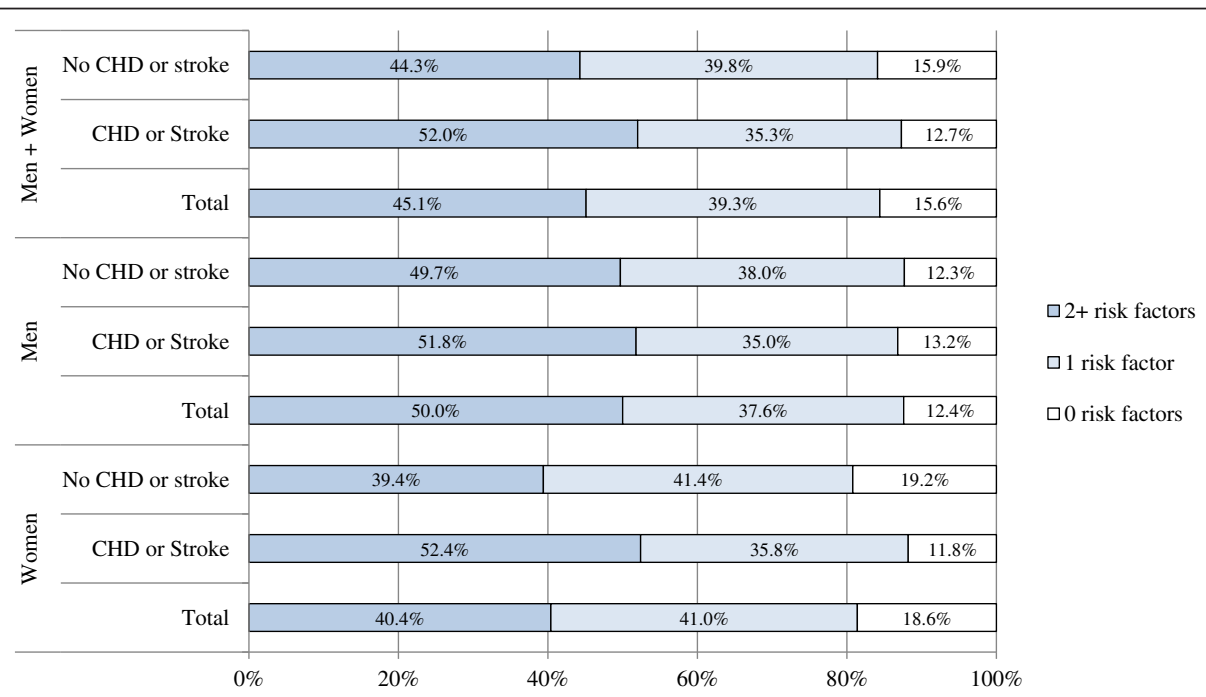

Fig. 2 Combination of five behavioural risk factors (\%) in adults aged 40-79 years with and without coronary heart disease (CHD) and stroke. The prevalences were stratified for sex and group with and without coronary heart disease (CHD) and stroke. The following behavioural risk factor categories were included: daily smoking, physical activity $<2.5 \mathrm{~h} / \mathrm{week}<2$ portions of fruit/day, alcohol intake $>10 \mathrm{~g} /$ day in women or $>20 \mathrm{~g} /$ day in men, $\mathrm{BMI} \geq 30 \mathrm{~kg} / \mathrm{m}^{2}$ 
For comparison, in the SHARE survey the more stringent targets of $<140 / 90 \mathrm{mmHg}$ in general and $<130 / 80 \mathrm{mmHg}$ for patients with co-morbidities or high $\mathrm{CV}$ risk were reached by less than $60 \%$ of general practice patients and by less than half of patients treated by cardiologists/ internists [16]. The joint ESC 2012 guideline targets for hyperlipidaemia are mainly based on low-density lipoprotein (LDL) levels. We used TC and non-HDL since fasting level LDL data were not available for a sufficient number of participants. However, TC and non-HDL are established markers for increased cardiovascular risk and are independent of fasting time $[17,18]$. The TC targets were more often reached by the CHD or stroke group than by the group without CHD or stroke, which is similar to previous findings [19] and most likely reflects more intensive lipid-lowering therapy among people with prior $\mathrm{CHD}$ or stroke. However, almost $90 \%$ of the CHD or stroke group exceeded the stringent non-HDL target.

Except for physical inactivity, prevalence of behavioural risk factors was higher among men. Other studies found similar results concerning physical activity [20], smoking [5, 21], BMI [15] and fruit and vegetable intake [15]. Possible reasons include gender-specific cultural norms relating to lifestyle [22] and gender-specific responses to lifestyle. Higher prevalences for most modifiable risk factors were found among the age group 60-79 years compared to the younger group. This indicates the need for preventive interventions at early life stages, because the risk of CVD increases with the duration of risk factor exposure [3].

The strengths of our study include the large nationwide sample of community-dwelling adults, the highly standardized measurements and the detailed questionnaires. The most important limitation is that severely ill and institutionalized men and women were mainly not included in the study which may have led to an underestimation of the risk factor proportions and to the rather low stroke and CHD prevalence. Equally important, the group without prior CHD or stroke includes individuals in all risk categories including high risk. It is a heterogeneous group which is not in the main focus of the paper. Therefore, the main finding is that uncontrolled risk factors are currently still highly prevalent both in the overall group (general population) and in the group with prior CHD or stroke, a clearly high-risk group likely to be aware of this high risk. A further limitation is the self-reported diagnosis of hypertension and dyslipidaemia which may have led to an underestimation of the prevalence of these diseases. However, information on prior diagnosis was used only to calculate awareness of elevated BP and elevated TC.

The risk factors in this analysis are all among the top risk factors contributing to the Global Burden of Disease both 1990 and 2010 [23]. It is never too late for improvements in behavioural risk factors, as illustrated by a $35 \%$ reduction of CVD events in 4 years in adults aged 45 years and older who switched to a healthy lifestyle [2]. Clearly, to individuals and to treating physicians it may appear more intuitive to put effort into lifestyle changes and enrol in prevention interventions in high-risk situations [24] where the number-needed-totreat to prevent an event is low. However, population benefits are larger if healthy lifestyles are adopted early on in order to prevent or delay hypertension, dyslipidaemia, obesity and chronic diseases [25, 26]. Action is required both at the health care system and societal level. Individuals may need treatment, but more often they need knowledge, motivation and accessible, convenient and attractive opportunities for improved lifestyle. For example, health education through mass media has been shown to be cost-effective to limit CVD [27]. The key to population-wide risk factor changes is clearly a combination of personal and non-personal interventions.

\section{Conclusion}

In conclusion, our study suggests that there is still a high prevention potential for adults in the general population and in the group with prior CHD or stroke in Germany and that prevention programs should aim at several major risk factors and their interrelations.

\section{Additional files}

Additional file 1: Non-HDL target and prevalence of cardiovascular risk factors stratified for age group (40-59, 60-79).

Additional file 2: Prevalence of cardiovascular risk factors by obesity status, blood pressure level, and total cholesterol level.

\section{Abbreviations}

ATC: Anatomical therapeutic chemical; BMI: Body mass index; BP: Blood pressure; CHD: Coronary heart disease; CVD: Cardiovascular disease; LDL: Low-density lipoprotein; TC: Total cholesterol.

\section{Competing interests}

The authors declare that they have no competing interests.

\section{Authors' contributions}

JT and HN designed the study. JT conducted the present analysis and HN, $M B, C S N, G M, A G$ and $M E$ contributed to the analysis plan and to the interpretation of the results. JT and HN drafted the manuscript and MB, CSN, GM, AG and ME critically revised it for important intellectual content. All authors read and approved the final manuscript.

\section{Acknowledgements}

DEGS1 is primarily funded by the German Ministry of Health (BMG).

\section{Author details}

'Department of Epidemiology and Health Monitoring, Robert Koch Institute, Berlin, Germany. ${ }^{2}$ German Center for Cardiovascular Research (DZHK), Berlin, Germany. ${ }^{3}$ Department and Out-Patient Care of Neurology, Charité,

Universitätsmedizin Berlin, Berlin, Germany. ${ }^{4}$ Center for Stroke Research Charité, Universitätsmedizin Berlin, Berlin, Germany. ${ }^{5}$ German Center for Neurodegenerative Diseases (DZNE), Berlin, Germany. 
Received: 6 January 2015 Accepted: 11 June 2015

Published online: 24 July 2015

\section{References}

1. European Heart Network and European Society of Cardiology. European Cardiovascular Disease Statistics. 2012.

2. King DE, Mainous 3rd AG, Geesey ME. Turning back the clock: adopting a healthy lifestyle in middle age. Am J Med. 2007;120:598-603.

3. Perk J, De Backer G, Gohlke H, Graham I, Reiner Z, Verschuren M, et al. European Guidelines on cardiovascular disease prevention in clinical practice (version 2012). The Fifth Joint Task Force of the European Society of Cardiology and Other Societies on Cardiovascular Disease Prevention in Clinical Practice (constituted by representatives of nine societies and by invited experts). Eur Heart J. 2012;33:1635-701.

4. Banegas JR, Lopez-Garcia E, Dallongeville J, Guallar E, Halcox JP, Borghi C, et al. Achievement of treatment goals for primary prevention of cardiovascular disease in clinical practice across Europe: the EURIKA study. Eur Heart J. 2011;32:2143-52.

5. Kotseva K, Wood D, De Backer G, De Bacquer D, Pyörälä K, Keil U. Cardiovascular prevention guidelines in daily practice: a comparison of EUROASPIRE I, II, and III surveys in eight European countries. Lancet. 2009;373:929-40.

6. Scheidt-Nave C, Kamtsiuris P, Gößwald A, Holling H, Lange M, Busch M, et al. German health interview and examination survey for adults (DEGS) design, objectives and implementation of the first data collection wave. BMC Public Health. 2012;12:730.

7. Gößwald A, Lange M, Dölle R, Hölling H. The first wave of the German Health Interview and Examination Survey for Adults (DEGS1): Participant recruitment, fieldwork, and quality management. Bundesgesundheitsblatt Gesundheitsforschung Gesundheitsschutz. 2013;56:611-9.

8. Kamtsiuris P, Lange M, Hoffmann R, Schaffrath Rosario A, Dahm S, Kuhnert $R$, et al. The first wave of the German Health Interview and Examination Survey for Adults (DEGS1): Sample design, response, weighting and representativeness. Bundesgesundheitsblatt Gesundheitsforschung Gesundheitsschutz. 2013:56:620-30.

9. Krug S, Jordan S, Mensink GBM, Müters S, Finger J, Lampert T. Physical activity : Results of the German Health Interview and Examination Survey for Adults (DEGS1). Bundesgesundheitsblatt Gesundheitsforschung Gesundheitsschutz. 2013:56:765-71.

10. Burger M, Mensink GBM. High alcohol consumption in Germany: results of the German National Health Interview and Examination Survey 1998. Public Health Nutr. 2004;7:879-84.

11. Chang E, Canchola A, Lee V, Clarke C, Purdie D, Reynolds P, et al. Wine and other alcohol consumption and risk of ovarian cancer in the California Teachers Study cohort. Cancer Causes Control. 2007:18:91-103.

12. WHO Global InfoBase team. The SuRF Report 2. Surveillance of chronic disease Risk Factors: Country-level data and comparable estimates. Geneva: World Health Organization; 2005.

13. National Cholesterol Education Program Expert Panel on Detection, Evaluation, and Treatment of High Blood Cholesterol in Adults. Third Report of the National Cholesterol Education Program (NCEP) Expert Panel on Detection, Evaluation, and Treatment of High Blood Cholesterol in Adults (Adult Treatment Panel III) final report. Circulation. 2002;106:3143-421.

14. King DE, Mainous 3rd AG, Carnemolla M, Everett CJ. Adherence to healthy lifestyle habits in US adults, 1988-2006. Am J Med. 2009;122:528-34.

15. Laccetti R, Pota A, Stranges S, Falconi C, Memoli B, Bardaro L, et al. Evidence on the prevalence and geographic distribution of major cardiovascular risk factors in Italy. Public Health Nutr. 2013;16:305-15.

16. Erdine S, Redon J, Bohm M, Ferri C, Kolloch R, Kreutz R, et al. Are physicians underestimating the challenges of hypertension management? Results from the Supporting Hypertension Awareness and Research Europe-wide (SHARE) survey. Eur J Prev Cardiol. 2013;20:786-92.

17. Scheidt-Nave C, Du Y, Knopf H, Schienkiewitz A, Ziese T, Nowossadeck E, et al. Prevalence of dyslipidemia among adults in Germany : Results of the German health interview and examination survey for adults (DEGS 1). Bundesgesundheitsblatt Gesundheitsforschung Gesundheitsschutz. 2013;56:661-7.

18. Robinson JG, Wang S, Smith BJ, Jacobson TA. Meta-analysis of the relationship between non-high-density lipoprotein cholesterol reduction and coronary heart disease risk. J Am Coll Cardiol. 2009;53:316-22.
19. Steinhagen-Thiessen $E$, Bramlage $P$, Losch $C$, Hauner $H$, Schunkert $H$, Vogt $A$, et al. Dyslipidemia in primary care-prevalence, recognition, treatment and control: data from the German Metabolic and Cardiovascular Risk Project (GEMCAS). Cardiovasc Diabetol. 2008;7:31.

20. Stranges S, Guallar E. Cardiovascular disease prevention in women: a rapidly evolving scenario. Nutr Metab Cardiovasc Dis. 2012;22:1013-8.

21. Tanuseputro P, Manuel DG, Leung M, Nguyen K, Johansen H, Canadian Cardiovascular Outcomes Research T. Risk factors for cardiovascular disease in Canada. Can J Cardiol. 2003;19:1249-59.

22. Courtenay WH. Constructions of masculinity and their influence on men's well-being: a theory of gender and health. Soc Sci Med. 2000;50:1385-401.

23. Murray CJ, Lopez AD. Measuring the global burden of disease. N Engl J Med. 2013;369:448-57.

24. van Wyk JT, van Wijk MA, Sturkenboom MC, Moorman PW, van der Lei J. Identification of the four conventional cardiovascular disease risk factors by Dutch general practitioners. Chest. 2005;128:2521-7.

25. Rose G. Strategy of prevention: lessons from cardiovascular disease. Br Med J (Clin Res Ed). 1981;282:1847-51.

26. Rose G. Sick individuals and sick populations. Int J Epidemiol. 2001;30:427-32.

27. Murray CJ, Lauer JA, Hutubessy RC, Niessen L, Tomijima N, Rodgers A, et al. Effectiveness and costs of interventions to lower systolic blood pressure and cholesterol: a global and regional analysis on reduction of cardiovasculardisease risk. Lancet. 2003;361:717-25.

\section{Submit your next manuscript to BioMed Central and take full advantage of:}

- Convenient online submission

- Thorough peer review

- No space constraints or color figure charges

- Immediate publication on acceptance

- Inclusion in PubMed, CAS, Scopus and Google Scholar

- Research which is freely available for redistribution

Submit your manuscript at www.biomedcentral.com/submit
C BioMed Central 